Review

\title{
Analytical and Theranostic Applications of Gold Na- noparticles and Multifunctional Nanocomposites
}

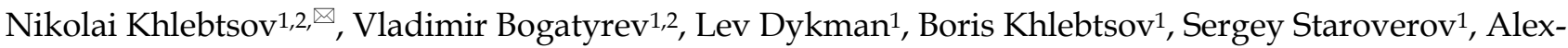 \\ ander Shirokov ${ }^{1}$, Larisa Matora ${ }^{1}$, Vitaly Khanadeev ${ }^{1}$, Timofey Pylaev ${ }^{1}$, Natalia Tsyganova ${ }^{3}$, Georgy Ter- \\ entyuk 2,3 \\ 1. Institute of Biochemistry and Physiology of Plants and Microorganisms, Russian Academy of Sciences (IBPPM RAS), Russian Federa- \\ tion; \\ 2. Saratov State University, Russian Federation; \\ 3. Ulyanovsk State University, Russian Federation.
}

\begin{abstract}
$\triangle$ Corresponding author: khlebtsov@ibppm.sgu.ru (Nikolai Khlebtsov).
() Ivyspring International Publisher. This is an open-access article distributed under the terms of the Creative Commons License (http://creativecommons.org/ licenses/by-nc-nd/3.0/). Reproduction is permitted for personal, noncommercial use, provided that the article is in whole, unmodified, and properly cited.
\end{abstract}

Received: 2012.12.15; Accepted: 2013.01.22; Published: 2013.02.20

\begin{abstract}
Gold nanoparticles (GNPs) and GNP-based multifunctional nanocomposites are the subject of intensive studies and biomedical applications. This minireview summarizes our recent efforts in analytical and theranostic applications of engineered GNPs and nanocomposites by using plasmonic properties of GNPs and various optical techniques. Specifically, we consider analytical biosensing; visualization and bioimaging of bacterial, mammalian, and plant cells; photodynamic treatment of pathogenic bacteria; and photothermal therapy of xenografted tumors. In addition to recently published reports, we discuss new data on dot immunoassay diagnostics of mycobacteria, multiplexed immunoelectron microscopy analysis of Azospirillum brasilense, materno-embryonic transfer of GNPs in pregnant rats, and combined photodynamic and photothermal treatment of rat xenografted tumors with gold nanorods covered by a mesoporous silica shell doped with hematoporphyrin.
\end{abstract}

Key words: Gold nanoparticles, multifunctional nanocomposites, immunoassay, DNA detection, cell bioimaging, mycobacteria, Azospirillum brasilense, photodynamic and photothermal therapy, placental barrier, materno-embryonic transfer of gold nanoparticles.

\section{Introduction}

In the past decade, gold nanoparticles (GNPs) have been widely used in various biomedical applications, including analytical chemical and biological sensing; genomics and immunoassays; optical bioimaging and monitoring of cells and tissues; detection and photodynamic therapy of pathogenic microorganisms; detection and photothermolysis of cancer cells and tumors; wound repair; and targeted delivery of drugs, peptides, DNA, and antigens $[1,2,3]$. The unique optical properties of GNPs are related to localized plasmonic excitations in metal nanostructures $[4,5]$ interacting with light. These excitations result in resonance-enhanced local fields and, accordingly, in enhanced optical phenomena such as absorption, Mie scattering, Raman scattering, and various nonlinear effects [6].

Multifunctional nanocomposites that combine therapeutic, diagnostic, and sensing modalities in a single nanostructure are widely used in a new field of nanobiotechnology called theranostics $[7,8,9,10,11,12,13]$. Although the term "theranostics" has been employed for the first time quite recently [7, $14]$, it is now rapidly growing and promising field at the crossroads of plasmonics and nanomedicine [15, 
16]. The first demonstration of the use of GNPs with various sizes and shapes for theranostic nanomedicine appeared in the papers by Loo et al. [17] (for gold nanoshells), Lapotko et al. [18] (for gold nanospheres), and Hleb et al. [19] (for gold nanorods). In 2010, Lukianova-Hleb et al. [11] presented a complete concept of theranostics. At present, multifunctional GNP-based nanocomposites [20] offer new theranostic modalities by combining the unique optical properties of plasmonic GNPs with the properties of mesoporous silica functionalized with an appropriate photosensitizer (PS) and molecular probes [21]. Another example is magnetic iron-oxide-based nanoparticles and nanocomposites combining magnetic resonance imaging with cancer-targeting moieties [22]. When using GNPs and nanocomposites in vivo, researchers inevitably come up against issues of particle biodistribution, pharmacokinetics, and possible particle toxicity $[23,24]$.

In this minireview, we give a short summary of our recent efforts in applications of GNPs and nanocomposites to analytical biosensing, visualization and bioimaging of cells, antimicrobial photodynamic treatment, in vivo biodistribution, and photothermal therapy of xenografted tumors. Besides our recently published reports, we discuss new data on dot immunoassay diagnostics of mycobacteria, multiplexed immunoelectron microscopy analysis of Azospirillum brasilense, materno-embryonic transfer of GNPs in pregnant rats, and combined photodynamic and photothermal treatment of rat xenografted tumors with gold nanorods covered by a mesoporous silica shell doped with hematoporphyrin.
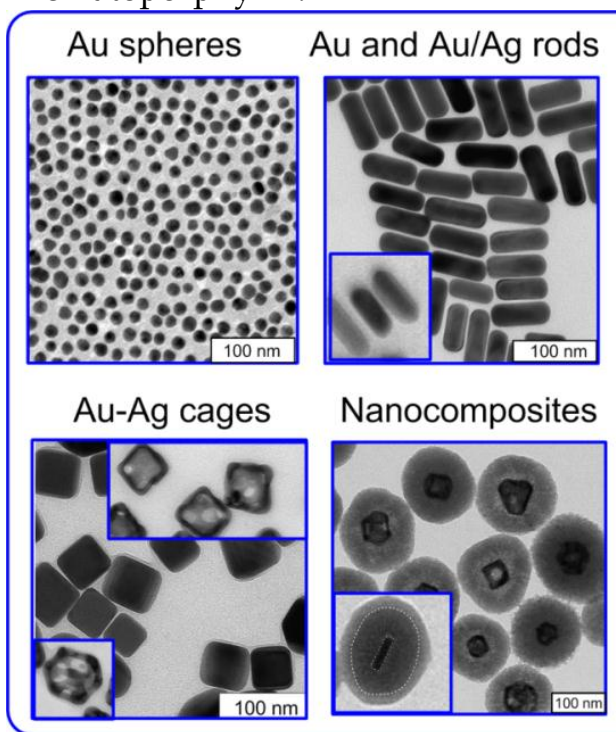

\section{Engineering and spectral tuning of GNPs for biomedical applications}

Despite the centuries-old history of colloidal gold [1], a breakthrough step in biomedical applications of GNPs was made by Faulk and Taylor in 1971 [25]. They conjugated antibodies with colloidal gold for direct electron microscopic visualization of Salmonella surface antigens, preparing the first immunochemical marker based on colloidal gold conjugates. Although the use of colloidal-gold biospecific conjugates in biomedicine still remains very active, these GNPs are not free from several fundamental drawbacks. First, the absorption and scattering cross sections of stable 15-30-nm gold nanospheres are low, whereas larger particles have greatly decreased colloidal stability. Second, because of the strong light absorption of biological tissues and fluids, the localized plasmon resonances (LPRs) of GNPs should be properly tuned to NIR transparency window 650-900 $\mathrm{nm}$ [26]. Thanks to the rapid progress in convenient technologies of GNP fabrication [27], biomedical researchers can now examine and use various types of GNPs and NCs to meet specific requirements of their experiments. Figure 1 shows a gallery of GNPs and NCs fabricated in our laboratory at IBPPM RAS for analytical, diagnostic, and therapeutic studies. Of course, this picture illustrates only a fraction of the currently available GNPs $[1,2,27]$, and it should be considered as an attempt to show a cross section of our work in this area, rather than as a comprehensive list.

Figure I. Examples of plasmonic GNPs: I6-nm Au nanospheres [28]; gold nanorods [29] and gold nanorods with silver coatings (inset) [30]; $\mathrm{SiO}_{2} / \mathrm{Au}$ nanoshells [3I]; gold nanostars [32]; silver nanocubes and $\mathrm{Au}-\mathrm{Ag}$ nanocages obtained from them (insets) [33]; nanocomposites containing a gold nanorod or nanocage core and a mesoporous silica shell doped with hematoporphyrin [34]; hollow mesoporous silica spheres and nanorattles containing gold nanocages; plasmonic nanopowders of gold nanospheres, nanorods, nanostars, and $\mathrm{Au}-\mathrm{Ag}$ nanocages $[32,35]$. 
Although the spectral tuning of GNP plasmonic properties can be made by several means [36], only few possibilities have proven to be robust and convenient in practice. Namely, the LPR of gold nanorods $[2,37]$ and $\mathrm{SiO}_{2} / \mathrm{Au}$ nanoshells [38] can be tuned to the NIR range by synthetically varying their aspect ratio [39] or core/shell radii [40], respectively (Fig. 2). For spectral tuning within the vis-NIR region, one can use gold nanorods with thin silver coatings [41] or $\mathrm{Au}-\mathrm{Ag}$ nanocages with a variable $\mathrm{Au}$ : Ag composition achieved by a galvanic replacement reaction [33, 42] (Fig. 2).

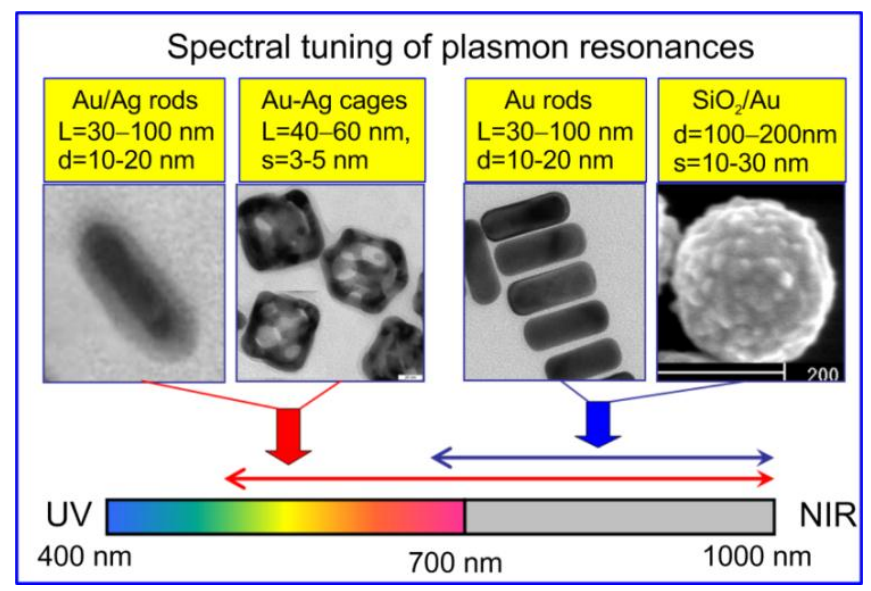

Figure 2. Spectral tuning of gold nanorods with silver coatings and $\mathrm{Au}-\mathrm{Ag}$ nanocages across vis-NIR spectral bands and of gold nanorods and $\mathrm{SiO}_{2} /$ Au nanoshells across red-NIR spectral bands. On the top of the TEM images, the typical geometrical parameters of GNPs are indicated: nanorod diameter $(d)$ and length $(L)$, nanocage edge length $L$ and wall thickness $(s)$, nanoshell outer diameter $(d)$ and gold shell thickness (s).

\section{GNPs in analytical biosensing and di- agnostics}

\section{I Homophase immunoassays}

For biomedical applications, the GNP surface should be modified with a stabilizing ligand (e.g., PEG-SH) or with a molecular probe (e.g., antibodies, oligonucleotides, peptides, carbohydrates, folic acid, etc.). Such nanostructures are called bioconjugates, whereas the attachment of biomacromolecules to the NP surface is often called functionalization $[1,43]$.

In 1980, Leuvering et al. [44] introduced a new homophase immunoassay they called the sol particle immunoassay (SPIA). In this method, the biospecific interaction between target molecules in solution and probe molecules of GNP conjugates results in GNP aggregation. When GNPs approach each other, the red color of the gold colloid changes to purple or gray, while their absorption spectra become broadened and red-shifted $[4,45]$. These changes in absorption spectra can easily be detected visually or with a routine spectrophotometer. An optimized variation of SPIA was used subsequently to detect human chorionic gonadotropin [46], Alzheimer's disease markers [47], hepatitis B virus in blood [48], and other substances [1]. A new SPIA version using microplates and an ELISA reader, with colloidal-gold-conjugated trypsin as a specific agent for proteins, was devised by Dykman et al. [49]. Further information about homophase immunoassays can be found in Refs. [1, 43].

\subsection{Label-free DNA detection}

The conventional strategy for nucleic acid detection is based on the polymerase chain reaction (PCR) [50], which allows quantitative DNA determination with high specificity, sensitivity, efficiency, and low contamination risk [51]. Despite its almost routine applications, in certain circumstances (e.g., in warfare or under the field conditions), it is desirable to have a rapid and simple qualitative test for primary DNA detection. In 1996, Mirkin et al. introduced a new GNP-based platform for colorimetric DNA detection [52]. The different ability of single- and double-stranded oligonucleotides to stabilize GNPs in solution has been used to design several label-free hybridization assays based on optical changes associated with GNP aggregation [53]. In particular, for systems containing DNA and GNPs, the dynamic light scattering detection of DNA has been proven to be more sensitive than the usual spectrophotometry [54].

Recently, we introduced a new genosensing approach employing CTAB (cetyltrimethylammonium bromide)-coated positively charged colloidal GNPs to detect target DNA sequences by using absorption spectroscopy and dynamic light scattering [29]. Figure 3a illustrates the basic principles underlying this DNA assay. The phosphate groups of zwitterion ssDNA molecules can interact with quaternary amines of CTAB without loss of GNP stability. The addition of a complementary $(+\mathrm{CDNA})$ target results in the formation of DNA duplexes (dsDNA), which are polyanions and can act as "glue" [55] to aggregate cationic particles. A more detailed consideration can be found in Pylaev et al. [29]. Particle aggregation can be monitored by absorption and differential light scattering spectroscopy or by DLS measurements of the particle-size distribution. 

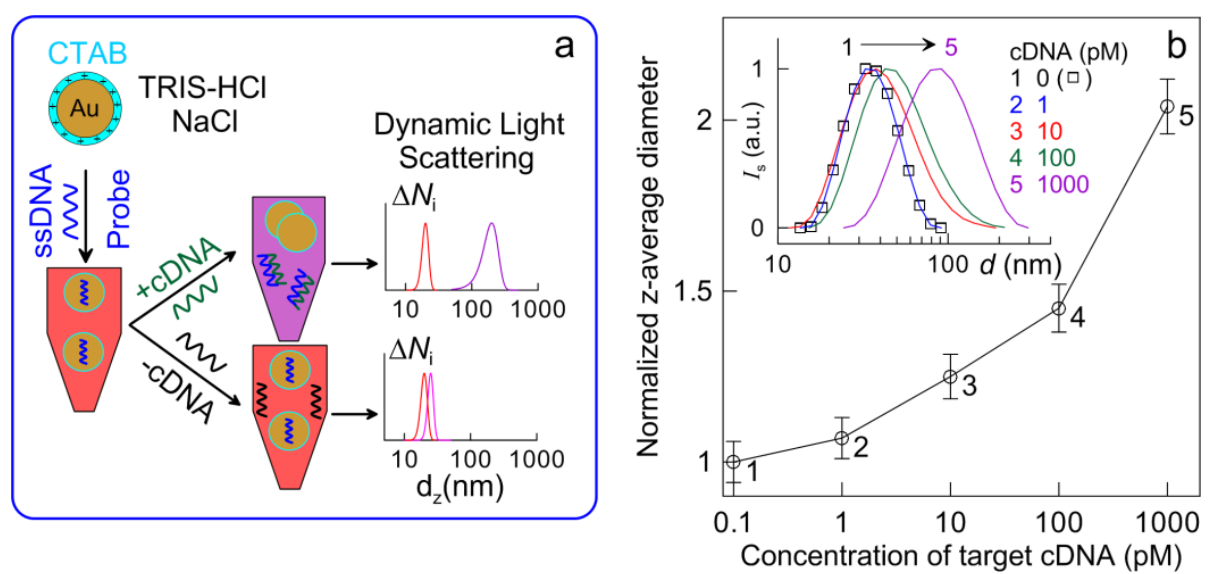

Figure 3. (a) Schematic representation of the colorimetric and DLS methods for differentiating between complementary (+cDNA) and noncomplementary (-cDNA) oligonucleotides by using CTAB-coated positively charged gold nanospheres. (b) Concentration dependence of DLS z-average diameter normalized to that of $16-\mathrm{nm}$ CTAB-coated particles in a mixture of hybridization buffer and probe PI ssDNA (HIV-I U5 sequence 5'-ATGTGGAAAATCTCTAGCAGT-3'). The bars represent \pm SD $(n=5)$. The inset shows DLS intensity-size distributions of 25-nm CTAB-coated particles in a mixture of hybridization buffer and probe PI ssDNA after the addition of target cDNA HIV-I U5 at concentrations of 0 (I), I (2), I0 (3), 100 (4), and 1000 PM (5). Similar results were obtained for P2 probe 5'-TCCTGCAGATACACTCCCACCAA-3' and T2 cDNA target [29].

For proof-of-the-concept experiments, a 21-mer ssDNA from the human immunodeficiency virus type 1 HIV-1 U5 long terminal repeat sequence (P1) and a 23-mer ssDNA from the Bacillus anthracis cryptic protein and protective antigen precursor $(\mathrm{P} 2)$ genes were used as ssDNA models. With cationic CTAB-coated GNPs, this method is easy to implement and possesses excellent feasibility with retention of comparable sensitivity - a $0.1 \mathrm{nM}$ concentration of target cDNA (T1 and T2) can be detected with the naked eye and $10 \mathrm{pM}$ by DLS measurements (Fig. 3b). The specificity of our method is illustrated by successful DLS detection of 1-3 base mismatches in cDNA sequences for both DNA models: SBM1 5'-ACTGCTAG ATATTTTCCACAT-3' and TBM1 5'-ACTTCTAGA TATTTTTCACAT-3' sequences for P1 ssDNA, and SBM2 5'-TTGGTTGGAGTGTATCTGCAGGA-3' and TBM2 5'-TTGGTTGGAGTTTATCTGCATGA-3' for P2 ssDNA. These results suggest that the cationic GNPs and DLS can be used for genosensing under optimal DNA hybridization conditions without any chemical modifications of the particle surface with ssDNA molecules and signal amplification.

\subsection{Immunodot assay using gold nanospheres and $\mathrm{SiO}_{2} / \mathrm{Au}$ nanoshells}

Solid-phase immunoassays are based on the adsorption of antigens onto a solid substrate followed by binding of biospecific labels to the adsorbed target molecules. In its membrane version, the solid-phase immunoassay can be called dot immunoassay, as usually a drop of analyte is spotted in the center of a drawn 5-mm square and the reaction outcome looks like a colored dot. The simplicity of analyses and the saving of antigens and reagents allow one to implement solid-phase immunoassays in the laboratory, in the field, or even under domestic circumstances to detect proteins (Western blotting), DNA (Southern blotting), or RNA (Northern blotting) (see the relevant references in [56]).

In spite of its attractive simplicity and efficiency, the colloidal gold dot-immunoassay is not free of drawbacks such as moderate sensitivity and long time of detection. In our work [56], we reported on the first application of $\mathrm{SiO}_{2} / \mathrm{Au}$ nanoshells to a solid-phase dot immunoassay. Fifteen-nm colloidal GNPs and three types of $\mathrm{SiO}_{2} / \mathrm{Au}$ nanoshells (100-, 140-, and $180-\mathrm{nm}$ silica core and $15-\mathrm{nm}$ gold shell thickness) were studied in our experiments. Normal rabbit serum (the target IgG molecules) and sheep antirabbit antibodies (the probing molecules) were used as a biospecific model. The minimal detection limit for IgG target molecules was about $15 \mathrm{ng}$ in the case of a standard dot-assay protocol based on 15-nm colloidal gold particles conjugated with probing molecules. In contrast to this observation, simple replacement of 15-nm gold labels by $\mathrm{SiO}_{2} / \mathrm{Au}$ nanoshell conjugates resulted in a drastic increase in detection sensitivity of up to $0.25 \mathrm{ng}$ in the case of $180 / 15$-nm nanoshells and of up to $0.5-1 \mathrm{ng}$ for 100/15 and 140/15 nanoshells (Fig. 4). These results have been explained by using a theoretical model developed in Ref. [57]. 


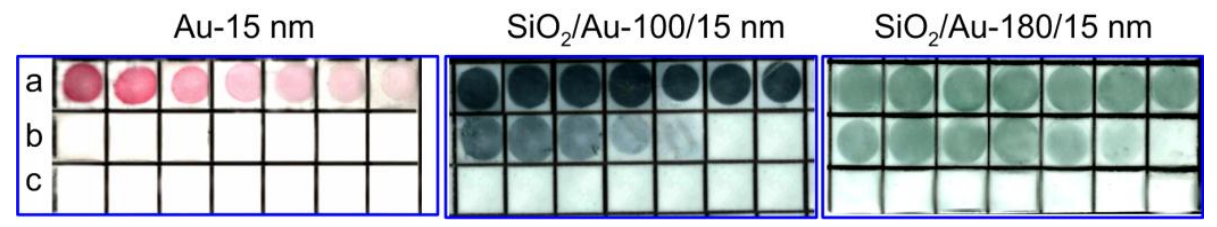

Figure 4. Dot immune overlay assay of normal rabbit serum $(\mathrm{a}, \mathrm{b})$ by using suspensions of conjugates of $15-\mathrm{nm} \mathrm{GNPs}$ and $\mathrm{SiO} / \mathrm{Au}$ nanoshells (100- and I80-nm silica core diameters and I5-nm gold shell) with sheep antirabbit antibodies. The amount of lgG in the first square of the top row was I $\mu$ g, decreasing from left to right in accordance with twofold dilutions. The lower rows (c) correspond to the application of $10 \mu \mathrm{g}$ of bovine serum albumin to each square as a negative control. The detected analyte quantity was $15 \mathrm{ng}$ for 15 -nm GNPs and 0.4 and $0.2 \mathrm{ng}$ for $100 / 15-$ and $180 / 15-\mathrm{nm}$ nanoshells, respectively.

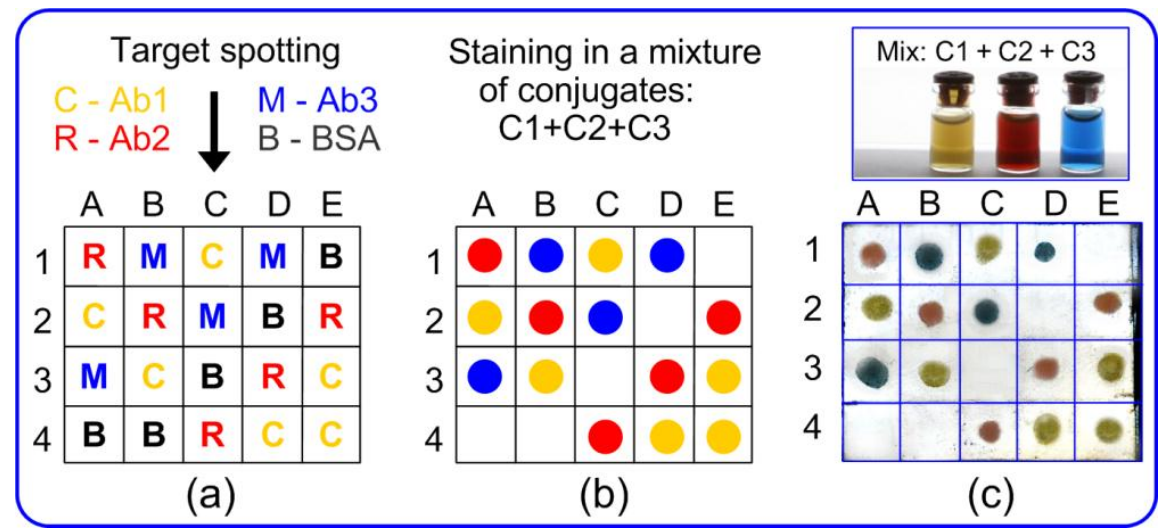

Figure 5. Scheme for the multiplexed dot immunoassay $(a, b)$ and its experimental verification (c). At the first step (panel a), antichicken rabbit antibodies $\mathrm{Abl}$ were spotted in squares $\mathrm{A} 2, \mathrm{~B} 3, \mathrm{CI}, \mathrm{D} 4, \mathrm{E} 3$, and E4; antirat rabbit antibodies Ab2 were spotted in squares AI, B2, C4, D3, and E2; antimouse rabbit antibodies Ab3 were spotted in squares A3, BI, C2, and DI; and for a negative control, BSA was spotted in squares A4, B4, C3, D2, and EI. The concentration of all analytes was $100 \mu \mathrm{g} / \mathrm{mL}$. After staining in a mixture of conjugates $(\mathrm{Cl}+\mathrm{C} 2+$ C3), the expected spot colors are shown in panel b. The experimental panel c confirms the expected assay results.

\subsection{Multiplexed immunodot and immunoelec- tron microsopy assays using $\mathrm{Au}-\mathrm{Ag}$ nanocages}

By using multicolored composite GNPs (Ag nanocubes, $\mathrm{Au}-\mathrm{Ag}$ alloy nanoparticles, and $\mathrm{Au}-\mathrm{Ag}$ nanocages), we recently developed a multiplexed variant of the immunodot assay [58]. As in the usual immunodot assay, the multiplexed variant is based on the staining of analyte drops on a nitrocellulose membrane strip by using multicolored nanoparticles conjugated with biospecific probing molecules. Composite $\mathrm{Au}-\mathrm{Ag}$ nanoparticles were prepared by a galvanic replacement reaction between $\mathrm{Ag}$ atoms of silver nanocubes and $\mathrm{Au}$ ions of tetrachloroauric acid [42]. Depending on the Ag: Au conversion ratio, the particle plasmon resonance was tuned from 450 to 700 $\mathrm{nm}$ and the suspension color changed from yellow to blue (Fig. 5).

The particles of yellow, red, and blue suspensions were functionalized with chicken, rat, and mouse IgG molecular probes, respectively. The multiplex capability of the assay is illustrated by a proof-of-concept experiment on simultaneous one-step determination of target molecules (rabbit antichicken, antirat, and antimouse antibodies) with a mixture of fabricated conjugates. Under naked eye examination, no cross-colored spots or nonspecific bioconjugate adsorption was observed, and the low detection limit was about $20 \mathrm{fmol}$ [58].

Thanks to their porous structure, the $\mathrm{Au}-\mathrm{Ag}$ nanocages can easily be discriminated from particles of similar size (and, moreover, from smaller or larger particles) in an analysis of TEM images with nanocage-based biomarkers. This property suggests utilization of $\mathrm{Au}-\mathrm{Ag}$ nanocages in combination with common colloidal gold nanospheres for a multiplexed immunoelectron microscopy visualization of at least two different antigen moieties. Figure 6 serves as an example of such multiplexed immunoelectron microscopy labeling. Shown here is the Azospirillum brasilense Sp245 bacterium, which lives on its own in soil or in close associations with plants in the rhizosphere, promoting the growth and increasing the yields of many plant species [59]. To discriminate between $\mathrm{H}$ antigens (the polar flagellum antigens, PFL) and $\mathrm{O}$ antigens of the lipopolysaccharide (LPS) capsule, we used two types of GNP conjugates. Namely, 15-nm colloidal GNPs were functionalized with antibodies 
against $\mathrm{H}$ antigens, and 50-nm $\mathrm{Au}-\mathrm{Ag}$ nanocages were functionalized with antibodies against $\mathrm{O}$ antigens. In the case of native bacteria, their LPS capsule covers both the bacterial surface and the polar flagellum (Fig. 6a).

Therefore, the PFL antigens are obscured by LPS and cannot be visualized with GNP conjugates. However, after a thorough but gentle washing and after labeling of bacteria with a mixture of functionalized 50-nm Au-Ag nanocages and 15-nm colloidal GNPs, one can easily visualize the spatial localization of two antigen types. To the best of our knowledge, this is the first time that LPS and PFL antigens have been simultaneously visualized by using an immunoelectron microscopy assay based on two different types of GNPs.

\subsection{Use of gold nanoparticles for immunoassay of mycobacteria}

Tuberculin is a mixture of filtrates derived from heat-killed cells of the mycobacterium $M$. tuberculosis, M. bovis, or M. avium. This allergen is used in the diagnostics of tuberculosis in the Mantoux skin test [60]. Here, we describe, for the first time, the use of antituberculin antibodies for immunoassay of mycobacteria. Figure 7 illustrates applications of the immunodot assay ("cell-gold immunoblotting") to mycobacteria, with the reaction products being visualized by using immunogold markers.
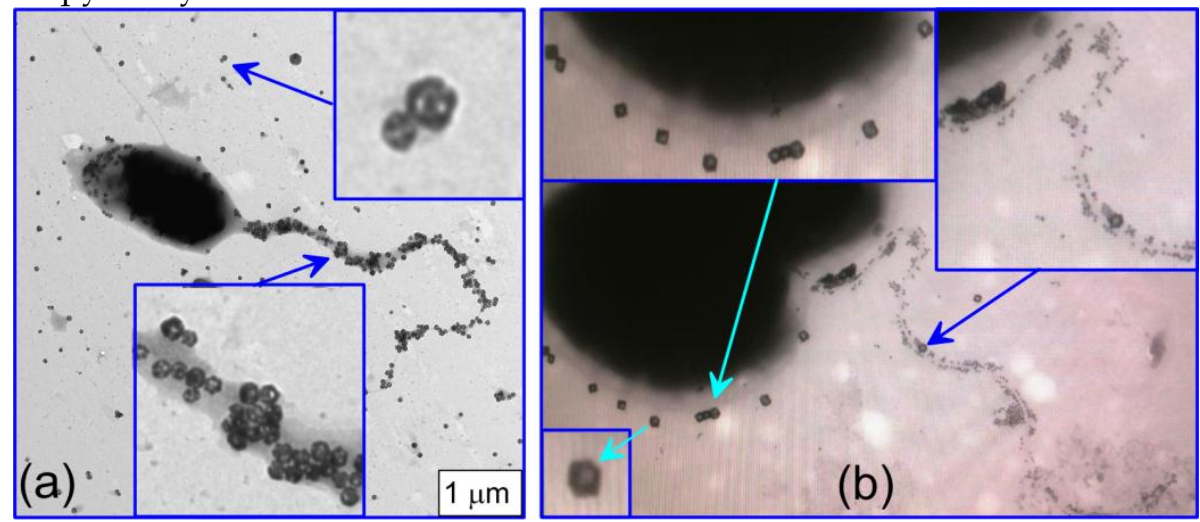

Figure 6. (a) TEM image of the bacterium A. brasilense Sp245 labeled with Au-Ag nanocages functionalized with O-specific antibodies. The bacteria were not washed before labeling, so the $\mathrm{O}$-specific antigens of the lipopolysaccharide capsule are clearly visualized both on the bacterial surface and on the polar flagellum. (b) TEM image of the same bacteria after a special washing procedure and simultaneous labeling with a mixture of O-specific conjugates (I5-nm GNPs + anti-LPS antibodies) and H-specific conjugates (50-nm $\mathrm{Au}-\mathrm{Ag}$ nanocages + anti-PFL antibodies). The insets clearly indicate quite specific labeling of the PFL and LPS antigens. The right upper inset also shows a small group of nanocage markers near the point of origin of the flagellum. This group corresponds to the residual LPS antigens that have remained after washing.

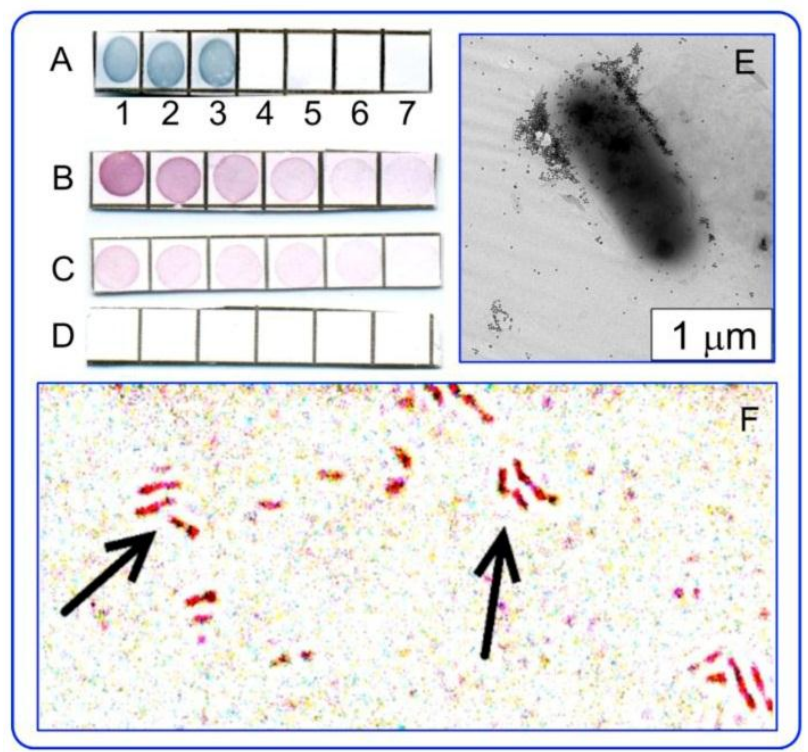

Figure 7. A - Specificity of antituberculin antibodies as determined by dot analysis using primary labeling with rabbit antituberculin antibodies and secondary labeling with conjugates of antirabbit antibodies with $160 / 20 \mathrm{~nm} \quad\left(\mathrm{SiO}_{2}\right.$ core/Au shell) nanoshells. Sampled antigens: I - rabbit antituberculin antibodies; 2 - tuberculin; 3 - M. bovis BCG; 4 - Escherichia coli XL-I blue; 5 Staphylococcus aureus 209-R; 6-Brucella abortus vaccine strain 82; 7 - brucellin. For samples I, 2, and 7, the concentrations were I $\mathrm{mg} / \mathrm{mL}$. B-D - Dot immunoanalysis of the mycobacteria $M$. bovis (B), M. smegmatis (C), and M. phlei (D) by using polyclonal antibodies to tuberculin (primary antibodies) and conjugates of antirabbit antibodies with I5-nm GNPs (secondary antibodies). Note the weak nonspecific coloration of $M$. smegmatis bacteria. $E$ TEM image of an $M$. bovis cell treated with antituberculin antibodies and labeled with conjugates of antirabbit antibodies with I5-nm GNPs. The GNP accumulation on the bacterial surface may reflect the localization of the tuberculin antigen. $\mathrm{F}$ - Light microscopy of $M$. bovis BCG treated with rabbit antituberculin antibodies and labeled with conjugates of antirabbit antibodies with I5-nm GNPs. The arrows point to mycobacteria. 
In this experiment, the antigen fraction was isolated from tuberculin PPD (BIOC Co., Russia) by salting out in an ammonium sulfate solution followed by HPLC purification. We introduced a novel strategy for the preparation of antibodies to tuberculin with the use of adjuvant properties of GNPs (for relevant references, see Dykman and Khlebtsov [1]). Conjugation of 15-nm GNPs with tuberculin, immunization of rabbits with the conjugates, and isolation and purification of rabbit antituberculin antibodies were done as detailed previously in Staroverov et al. [61]. The bacterial cultures (M. bovis BCG, E. coli XL1 blue, $S$. aureus $209-\mathrm{R}, B$. abortus vaccine strain $82, M$. phlei, and M. smegmatis) were fixed with acetone and were dispersed in PBS at a concentration of $1 \times 10^{9}$ cells $/ \mathrm{mL}$. Dot immunoassay of the strains was performed by sampling of stock dispersions on a Westran S membrane (Whatman, USA), blocking with a $2 \%$ dry milk dissolved in PBS, primary labeling with rabbit antituberculin antibodies and secondary labeling with conjugates of antirabbit antibodies with 15-nm GNPs or 160/20 nm ( $\mathrm{SiO}_{2}$ core/ Au shell) nanoshells (optical density of about 0.5 at LPR wavelengths). The labeled cells were analyzed with an optical DMI 3000 B (Leica, Germany) microscope and a Libra-120 TEM microscope (Carl Zeiss, Germany). Other experimental details can be found in Staroverov et al. [61].

It follows from Fig. 8 that the dot immunoassay confirms the specificity of antibodies (A-D) with respect to both soluble and corpuscular antigens, illustrates the distribution of the tuberculin antigen on the $M$. bovis surface (E) by using TEM images of labeled cells, and allows detection of $M$. bovis bacteria by using GNP conjugates and transmission light microscopy $(\mathrm{F})$.

In future work, we plan to use the GNP+tuberculin conjugates not only for obtainment of diagnostic antibodies, but also for development of tuberculin-based anti-tuberculosis vaccines. This can be considered as a new variant of theranostics, which can be called "prophynostics" (prophylaxes + diagnostics).

\section{Imaging of GNPs on and within cells by using combined optical-microscopy techniques}

GNPs are nonfluorescent probes that have been used actively in various bioimaging applications [62, 63] owing to their photostability, small toxicity, high light scattering efficiency, and ability to serve as carriers for different molecular cargos. Accordingly, GNPs are quite suitable for the visualization of living cells and dynamic processes occurring in them. In general, all optical imaging techniques fall into two broad categories: the linear response methods and the nonlinear response ones. The first category includes such methods as bright-field microscopy (TL, transmitted light illumination), dark-field microscopy (DF, plasmonic resonance scattering at oblique illumination $[64,65])$, the differential interference contrast (DIC, an interference pattern owing to the optical path gradients of the specimen; see the relevant references in review [66]), confocal laser resonance scattering [67] and two-photon luminescence [68] microscopies, and laser-induced scattering around a nanoabsorber (LISNA) [69]. The nonlinear techniques include the two-photon [70, 71] or multiphoton luminescence [72] of GNPs, the plasmonic enhanced multiphoton processes, the third harmonic generation [73], and coherent anti-Stokes Raman scattering (CARS) [66]. The most informative data come from combinations of different techniques (e.g., DIC + DF) and combination of plasmonic and fluorescent labels [74, 75, 76].

Below, we provide several illustrative examples with SPEV-2 and Egeria najas cells labeled with 50-nm colloidal gold nanospheres (NSPs), gold nanostars (NSTs, the outer size of about $80 \mathrm{~nm}$, the core size of about $50 \mathrm{~nm}$ ). Note that NSTs were fabricated according to a CTAB-assisted protocol [77]; therefore CTAB molecules can be desorbed during incubation with cells. For light microscopy examination, SPEV-2 cells were incubated with NSPs $\left(2 \times 10^{10}\right.$ particles $\left./ \mathrm{mL}\right)$ or NSTs $\left(5 \times 10^{9}\right.$ particles $\left./ \mathrm{mL}\right)$ for different times (typically, $24 \mathrm{~h}$ ) and then were incubated with propidium iodide (PI, $8 \mu \mathrm{g} / \mathrm{mL}$ ), acridine orange (AO, 8 $\mu \mathrm{g} / \mathrm{mL}$ ) and DAPI (50 $\mathrm{ng} / \mathrm{mL})$, both separately and in combination. In the case of E. najas, no dyes were applied. The TL, DIC, and DF images were recorded with a Leica LMD $7000(63 \times 0.75)$ objective. The DF, phase contrast (PC), and fluorescent (FL) images were obtained with a Leica DMI 3000 B microscope equipped with a Leica CLX $150 \mathrm{X}$ side illumination system. The confocal images were recorded with a Leica TCS SP5 confocal laser scanning microscope.

In the TL mode, only large NSP aggregates could be seen (Fig. 8)/ The DF and DIC modes were more suitable for the visualization of NSPs (c) and cells (d), whereas a DIC + DF (a) combination gave the best resolution for both cells and particles.

In Fig. 9, one can observe significant differences between left (NSPs) and right (NSTs) column images. In the PC and FL modes (panels a and c), clusters of NSPs appeared as dark spots because of the light absorption by particles and AO quenching, but in the FL + DF mode (panel e), one can clearly identify bright orange scattering from the NSP clusters. In contrast, we observed strong diffuse scattering from 
cells treated with NSTs (DF mode, panel f). In addition, the bright spots of nucleolus are evident in panels $b$ and $d$ in the PC and FL modes. This observation can be explained by single-particle distribution of NSTs within the cytoplasm, as positively charged as-prepared NSTs do not aggregate in the presence of cationic dyes, in contrast to NSps. Apparently, in such a complex environment as cellular cytoplasm, the NSTs maintain their dispersion owing to an adequate zeta-potential and/or steric hindrance. In a manner untypical of $\mathrm{AO}$, the yellow-brown coloration of the cells in panel (d) can be related to CTAB-assisted penetration of PI into the cytoplasm, resulting in a weak red coloration.

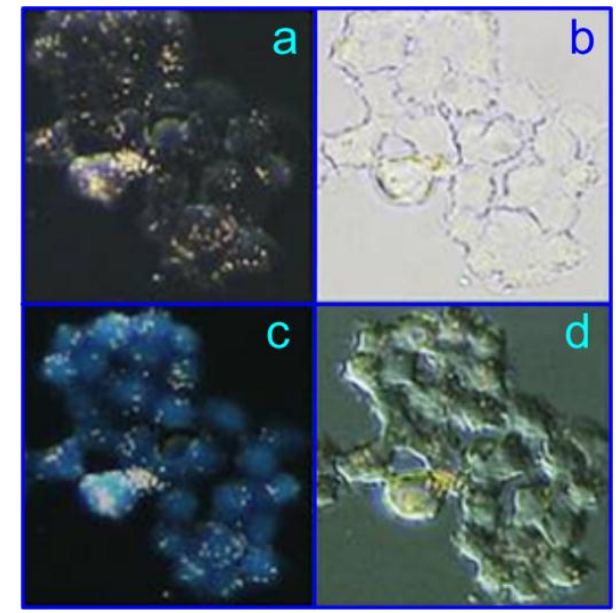

Figure 8. SPEV-2 cells labeled with NSPs $\left(2 \times 10^{10}\right.$ particles $\left./ \mathrm{mL}\right)$. Images were taken with a Leica LMD 7000 microscope in the following modes: DIC + DF (a), TL (b), DF (c), and DIC (d).

In Fig. 10a-c, the gold NSPs appear as red spots because of the intense light scattering at $633 \mathrm{~nm}$. Although the cationic AO dye predominantly binds to nucleic acids, it can also bind to proteins and carbohydrates, thus enhancing the cell nucleus and cytoplasm contrast (see the intense yellow spots and the weak yellow coloration, respectively). Thus, the combined imaging allowed GNPs to be visualized both on the surface and in the cytoplasm, whereas no GNPs were observed in the nucleus. Panel (d) illustrates intense scattering at $633 \mathrm{~nm}$ by NSTs on the cell surface and within the cells. The weak coloration of the cell nucleus in panel (d) can be explained by possible slight damage to the cell membrane, which may have been caused by CTAB desorbtion from NSTs. Finally, we note that the localization of NSTs within E. najas (panel e) is an exceptional observation, as usually GNPs are localized near the outer leaf surface.
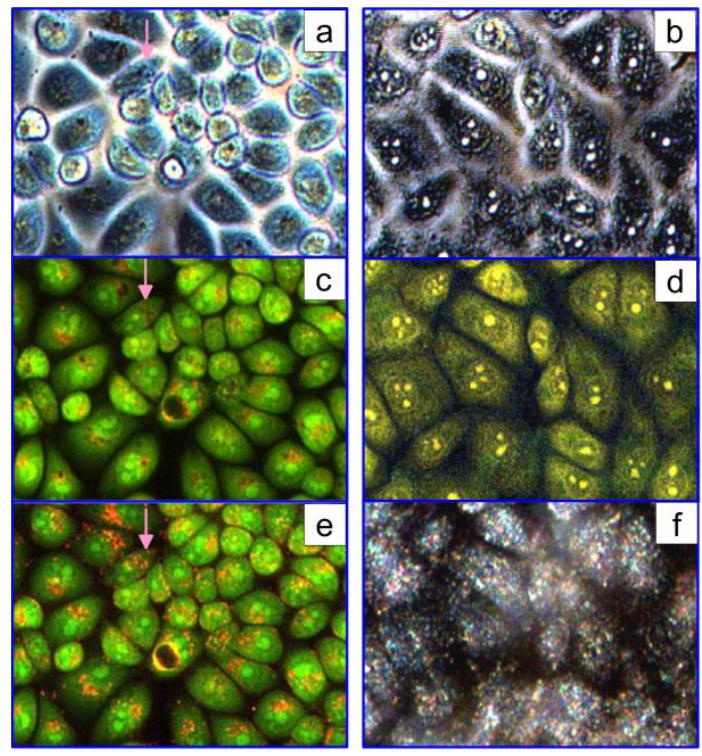

Figure 9. SPEV-2 cells incubated with NSPs (left column) and NSTs (right column). Images were taken with a Leica DMI 3000 B microscope (objective $20 \times 0.4 \mathrm{Ph} \mathrm{I}$, dichroic cube I3) in the following modes: PC (a, b), FL (c, d), FL + DF (e), and DF (f). The arrows in the left column indicate the clusters of NSPs in the prenuclear areas of the cells. Owing to the quenching of the $A O$ dye by NSPs, these clusters appear as dark spots in FL (c) and as bright spots in FL + DF (e).

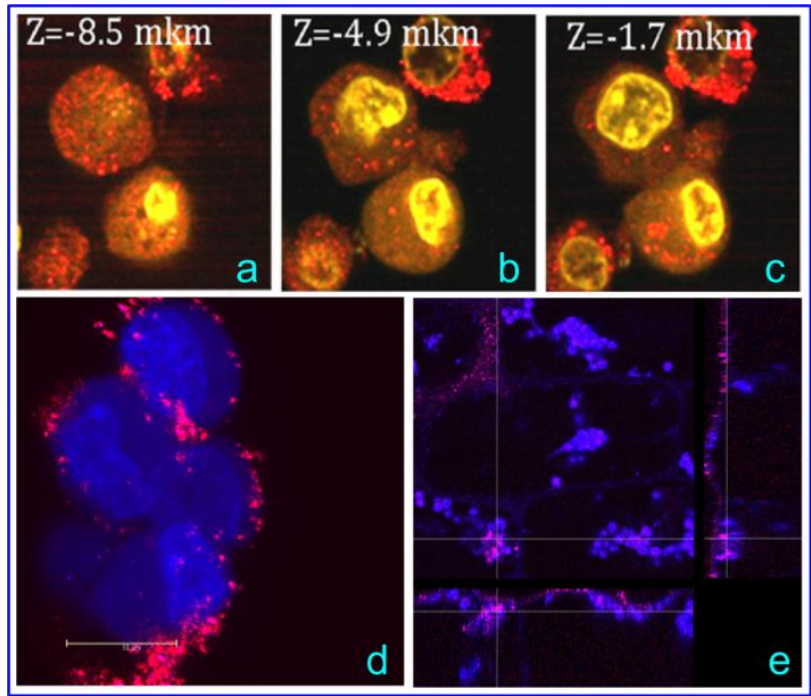

Figure 10. $(\mathrm{a}-\mathrm{c})$. Confocal images of SPEV-2 cells labeled with NSPs. The red spots correspond to the localization of NSPs on the cell surface and within the cells; the bright yellow areas correspond to AO within the cells. (d) The confocal optical section of SPEV-2 cells stained with DAPI and PI after 20-min incubation with NSTs. The image was taken with a Leica TCS SP5 [excitation at $543 \mathrm{~nm}$ and $633 \mathrm{~nm}$, fluorescence detection from 644 to $695 \mathrm{~nm}$ (false blue coloration), and scattering detection at $633 \mathrm{~nm}$ (true red coloration)]. (e) Optical sections of an E. najas leaf incubated with NSTs. The dashed lines indicate the locations of three projections: $X Y$ - left, $Y Z$ - right, and $X Z$ - bottom. The intersection of the lines indicates the colocalization of chloroplasts (blue spots) and NSTs (red spots) within the cells and near the leaf surface. 


\section{GNPs and nanocomposites in therapy}

\section{I Antimicrobial therapy of S. aureus 209 P}

Kuo et al. [78] first demonstrated bimodal (photothermal and photodynamic) suppression of antibiotic-resistant $S$. aureus bacteria with toluidine blue conjugated to gold nanorods. In a recent work [34], we fabricated multifunctional composite nanoparticles consisting of a plasmonic core [Au nanorods (NRs) or $\mathrm{Au}-\mathrm{Ag}$ nanocages (NCGs)] and a hematoporphyrin-doped silica shell. The dual photodynamic (PD) and photothermal (PT) activities of such nanoparticles against S. aureus $209 \mathrm{P}$ were studied and compared with the activities of the reference solutions: hematoporphyrin (HP) or silica-coated plasmonic nanoparticles. As PDT sensitizers, we used two types of nanocomposites: $\mathrm{NR} / \mathrm{SiO}_{2} / \mathrm{SiO}_{2}-\mathrm{HP}$ (particle concentration, $1.8 \times 10^{15} \mathrm{~L}^{-1} ; \mathrm{HP}$ concentration, $7 \mathrm{mg} / \mathrm{L}$ ) and $\mathrm{NCG} / \mathrm{SiO}_{2} / \mathrm{SiO}_{2}-\mathrm{HP}$ (particle concentration, $10^{14} \mathrm{~L}^{-1}$; $\mathrm{HP}$ concentration, $4 \mathrm{mg} / \mathrm{L}$ ). As comparison solutions, we used solutions of silica-covered nanorods $\left(\mathrm{NR} / \mathrm{SiO}_{2}\right)$ and nanocages $\left(\mathrm{NCG} / \mathrm{SiO}_{2}\right)$ with equivalent concentrations $\left(1.8 \times 10^{15} \mathrm{~L}^{-1}\right.$ and $10^{14} \mathrm{~L}^{-1}$, respectively) and HP solutions with concentrations corresponding to those for NCs (7 and $4 \mathrm{mg} / \mathrm{L})$. Bacteria were incubated with nanocomposites or with the reference solutions for $15 \mathrm{~min}$, which was followed by CW light irradiation with a few exposures of 5 to 30 min. To stimulate the PD and PT activities of the nanocomposites, we used LEDs (405 nm and $625 \mathrm{~nm}$ ) and a NIR laser $(808 \mathrm{~nm})$, respectively. We observed enhanced inactivation of $S$. aureus $209 \mathrm{P}$ by nanocomposites in comparison with the reference solutions (see, e.g., Fig. 11a). Using fluorescence micros- copy and spectroscopy, we explained the enhanced antimicrobial effect of the hematoporphyrin-doped nanocomposites by their selective accumulation in the vicinity of the bacteria (Fig. 11b-e).

\subsection{Biodistribution of GNPs and materno-fetal transfer of GNPs in rat pregnancy}

As the range of GNP types and their theranostic applications continues to increase, human safety concerns are gaining attention, which makes it necessary to better understand the potential toxicity hazards of these nanomaterials. At present, one of the major obstacles in the understanding of nanotoxicity is the broad range of experimental conditions under which biodistribution and toxicity effects have been evaluated in vitro and in vivo. In a recent review [24], we presented a detailed analysis of the data available on the in vitro and in vivo biodistribution and toxicity of most popular GNPs, including those shown in Fig. 1. In general, biodistribution over organs and tissues is strongly affected by particles size and shape and by the surface modifiers that determine particle charge. Potentially high toxicity is expected for small, 1-2-nm GNPs because of the possibility of their binding irreversibly to key biopolymers such as DNA. On the other hand, many experiments in vitro have not revealed notable toxicity of 3- to 100-nm GNPs, provided that the upper limit of the applied dose did not exceed a value of the order of $10^{12}$ particles $/ \mathrm{mL}$. The published data on experiments in vivo are rare and controversial. Nevertheless, one can expect moderate toxicity, if any, during short-period administration of GNPs at a daily dose lower than $0.5 \mathrm{mg} / \mathrm{kg}$.
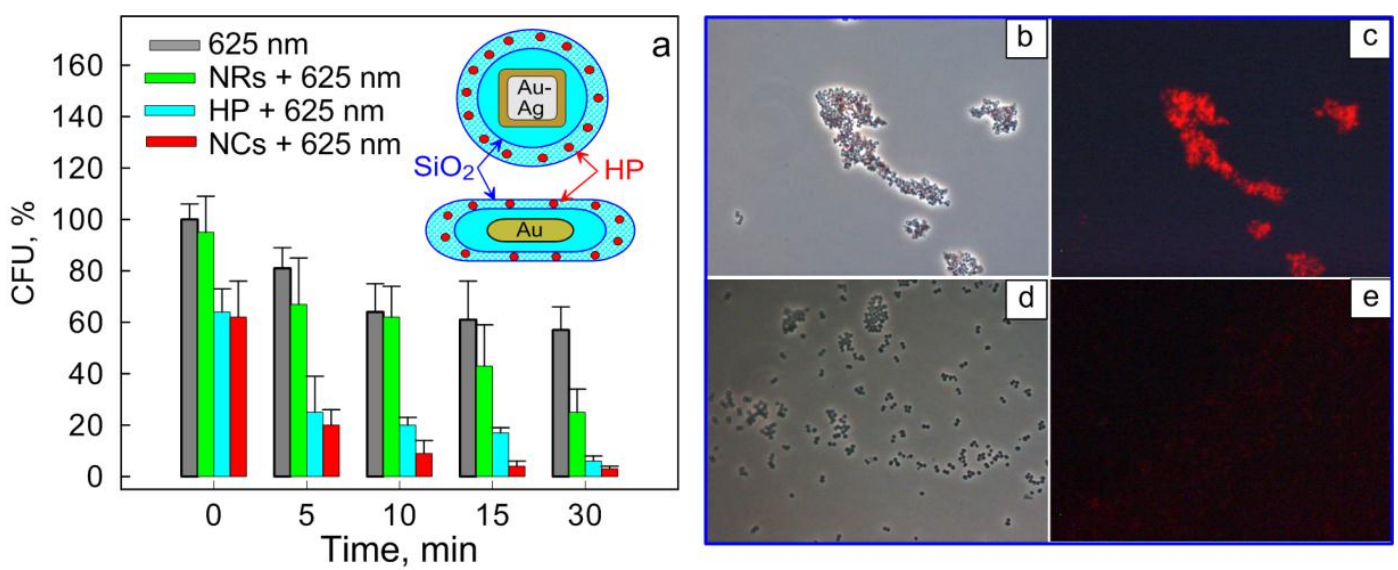

Figure II. (a) Viability of S. aureus (in terms of colony forming units, CFU) as a function of the irradiation time $\left(625 \mathrm{~nm}, 39 \mathrm{~mW} / \mathrm{cm}^{2}\right)$ after incubation with nanocomposites (NCs) based on nanorods (NRs). Before photodynamic treatment, bacteria were incubated in the dark for 15 min in solutions of PBS (gray), silica-coated nanoparticles (green), hematoporphyrin (HP) (blue; $0.7 \mathrm{mg} / \mathrm{L}$ ), and NCs (red). The inset shows schematic structures of the NCs. Transmission (b, d) and fluorescence (c, e) microscopic images of bacteria after incubation with $\mathrm{NR} / \mathrm{SiO}_{2} / \mathrm{SiO}_{2}-\mathrm{HP}$ composites (b, c), and HP solutions (d, e) [34]. 
The published data suggest the penetration of GNPs across the blood-brain or blood-retinal barriers to be critically size-dependent with an upper limit of about 15 to $20 \mathrm{~nm}$. The penetration of GNPs through the hematoplacental barrier and the potential fetotoxicity of GNPs at their exposure in pregnancy are important research fields of nanotoxicity. Surprisingly enough, there have been no published reports until recently [79, 80]. Yang et al. [79] investigated the effect of gestational age and nanoparticle composition on fetal accumulation of 13-nm maternally-administered ferritin-, PEG-, citrate-coated GNPs in mice. We studied the placental barrier permeability of white rats for 5- and 30-nm PEGylated GNPs $(5.1 \pm 0.6$ and $32 \pm 3.6 \mathrm{~nm}$, respectively), which was intravenously injected into pregnant female rats on day 10 of gestation at a dose of about $0.8 \mathrm{mg} \mathrm{Au} / \mathrm{kg}$ animal. GNPs in tissues were visualized by silver nitrate autometallography (Fig. 12), and the total Au content in the fetuses was evaluated by atomic absorption spectroscopy (AAS). In particular, GNPs were observed in the fetus, liver, and spleen, whereas AAS revealed an enhanced total gold content of 5-nm and 30-nm GNPs in fetuses (of about 0.2 and $0.25 \mu \mathrm{g}$, respectively) in comparison with controls. To the best of our knowledge, this is the first demonstration in vivo of the GNP penetration through the rat placental barrier. Despite the presence of GNPs in fetuses, no morphological changes were observed in the organs of fetuses examined.

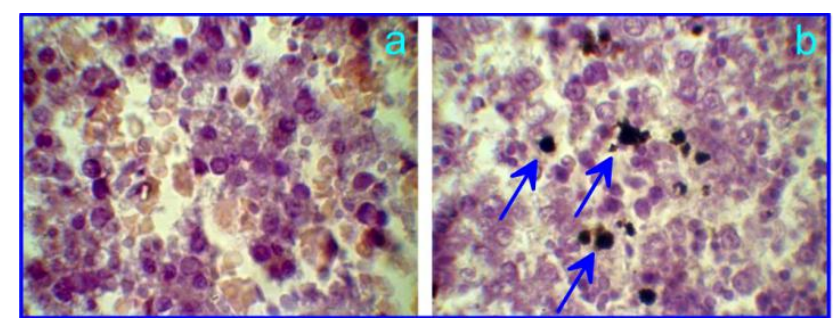

Figure 12. Liver of a rat fetus on the 10th gestational day after intravenous injection of control PBS solution (a) and 5-nm PEG-coated GNPs at a dose of $0.8 \mathrm{mg} \mathrm{Au} / \mathrm{kg}$ animal to a pregnant rat. The arrows indicate GNPs in the liver after silver nitrate autometallography.

\subsection{Comparison of the photothermal efficien- cies of GNPs and composites}

PT therapy of tumors is based on the preferential selective accumulation of GNPs and on the generation of heat [81] or nanobubbles [82, 83] sufficient to damage tumor tissues. As the scattering and absorption properties of different GNPs can vary signifi- cantly, it is desirable to compare their PT efficiencies. For example, such a comparison has been done by using extensive numerical simulations for gold nanospheres, nanorods, nanoshells, and various 1D-3D assemblies built from layered spheres [84]. Since that study, several reports have been published $[85,86,87,88]$ in which the PT efficiencies of gold nanorods and nanoshells were compared. Note that there are some contradictions between the published conclusions on the PT efficiencies of rods and shells, which are related, in part, to different definitions of the key quantities for the efficiency of light-heat conversion. A relevant discussion of the previously published results can be found in a recent paper by Pattani and Tunnell [89]. In our paper [33], we described the first experimental comparative study of the PT efficiencies of three particle types: $\mathrm{SiO}_{2} / \mathrm{Au}$ nanoshells, Au nanorods, and $\mathrm{Au}-\mathrm{Ag}$ nanocages. We found that the time-dependent temperature plots for all the three particle types were very similar, provided that their optical densities at the resonance wavelength $(810 \mathrm{~nm})$ were equal. However, the PT efficiency in terms of generated heat per unit metal mass was highest for nanocages, followed by rods and shells (Fig. 13a, inset) [33]. (Note that there was a misprint in Fig. 8 of Ref. [33] - the minute time scale should be read as the second scale). In the definition of the PT efficiency per unit metal mass, the monodisperse approximation for $\mathrm{Au}$ nanobox size and thickness was assumed. Accordingly, all the particles were assumed to be excited at plasmon resonance. Figure 13 also shows the comparative kinetics of heating for nanocages and nanocomposites containing a plasmonic core (nanocage) and a silica shell. It follows from the Fig. 13b plots that the silica shell does not affect the PT efficiency of composites. Similar results have been obtained for $\mathrm{Au}$ nanorods and $\mathrm{Au}$ nanorods with silica coatings (data not shown).

\subsection{Combined photodynamic and photother- mal therapy of xenografted tumors in rats}

Nanocomposites combining the PT and PD modalities can be used not only for antimicrobial treatment but also for a combined therapy of cancer. Here, we report preliminary data obtained with a model of xenografted tumors in rats. Specifically, the rat liver cancer cells PC-1 (kindly provided by Blokhin Cancer Research Center, Moscow) were implanted in male rats, and tumors were allowed to grow for about three weeks up to a $3 \mathrm{~cm}^{3}$ volume (Fig. 14a). Taking into account the fairly large tumor volume, our previous data on the distribution of GNPs [90] and nanocomposites [20] after systemic GNP administration, and the data by Huang et al. [91] on passive and active 
tumor targeting, we decided to inject nanocomposites directly into tumors at a dose of $400 \mu \mathrm{g}$ of gold. Then, the tumors were simultaneously irradiated by a combination of 633-nm red and 810-nm NIR CW lasers to stimulates the PD and PT antitumor activities of the nanocomposites. Figure $14 \mathrm{~b}$ and $\mathrm{c}$ illustrate photo- thermolysis of the tumor immediately after 20-min laser exposure and $72 \mathrm{~h}$ after treatment. Evidently, the tumor was completely eliminated after combined irradiation, whereas separate PD and PT treatment was less effective.
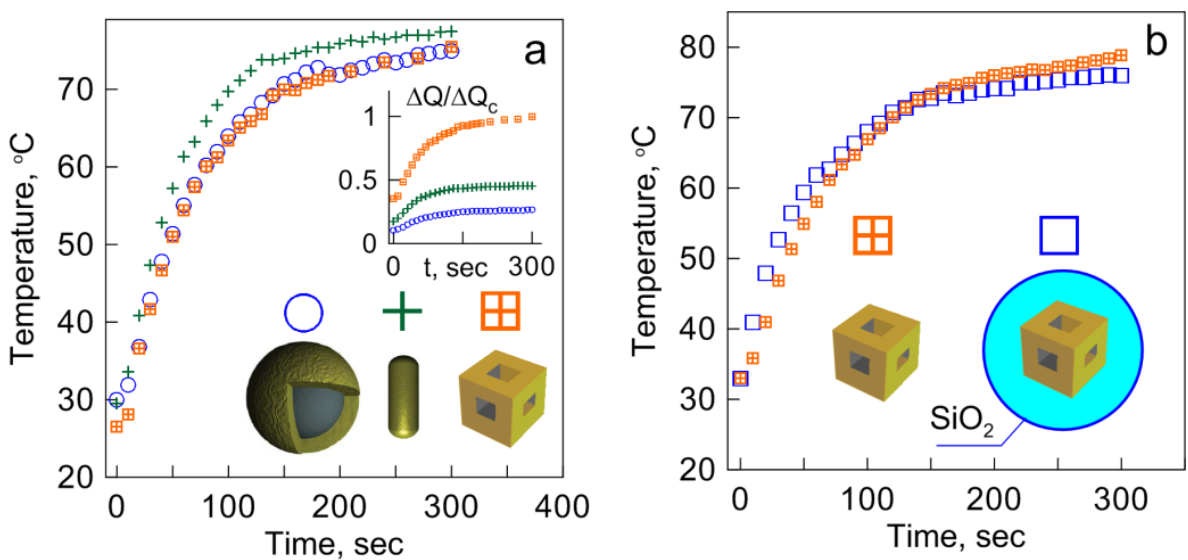

Figure 13. (a) Kinetics of suspension laser heating for $\mathrm{SiO}_{2} / \mathrm{Au}$ nanoshells, Au nanorods, and $\mathrm{Au}-\mathrm{Ag}$ nanocages [33]. The inset shows a comparison of the photothermal efficiencies of the particles in terms of normalized heat generation $\Delta \mathrm{Q}$ per unit metal mass. All curves are normalized to the $\Delta \mathrm{Qc}$ quantity for nanocages. (b) Kinetics of suspension laser heating for $\mathrm{Au}-\mathrm{Ag}$ nanocages and nanocomposites (nanocages with 50-nm silica coatings). Suspensions were irradiated by a diode laser at a power density of $2 \mathrm{~W} / \mathrm{cm}^{2}$ and a wavelength of $810 \mathrm{~nm}$, which was close to the plasmon resonance wavelengths of all three particle types: $\mathrm{SiO}_{2} / \mathrm{Au}$ nanoshells (core diameter of I60 nm, shell thickness of $20 \mathrm{~nm}$ ), Au nanorods (length of $40 \mathrm{~nm}$, diameter of $12 \mathrm{~nm}$ ), and Au-Ag nanocages (edge length of $54 \mathrm{~nm}$ ).

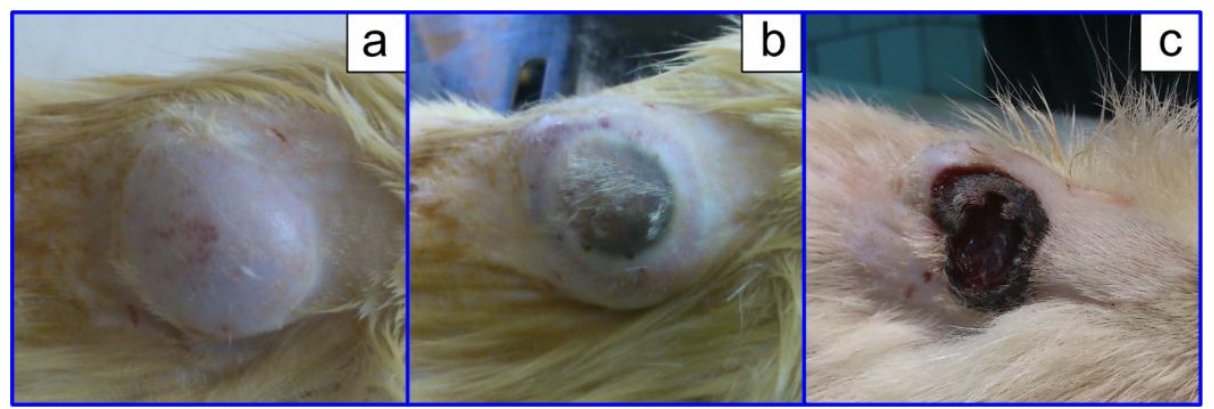

Figure 14. (a) Xenografted tumor (implanted rat liver cancer cells PC-I) after the administration of AuNRs/SiO $2-\mathrm{HP}_{\mathrm{P}}$ nanocomposites at a dose $400 \mu \mathrm{g}$ of gold directly to the tumor before irradiation. (b) The tumor after simultaneous 20-min exposure of 633-nm CW He-Ne laser $\left(160 \mathrm{~mW} / \mathrm{cm}^{2}\right)$ and 808-nm CW NIR laser $\left(2.2 \mathrm{~W} / \mathrm{cm}^{2}\right)$. (c) $72 \mathrm{~h}$ after combined irradiation.

\section{Conclusion}

We have discussed some topical applications of GNPs and nanocomposites in biology and biomedicine. Depending on the particular goal, the optical properties and multiple functions of GNPs and nanocomposites can be properly tailored through controllable variation in their size, shape, structure, composition, and surface functionalization. In particular, the $\mathrm{Au}$ nanorods and $\mathrm{Au}-\mathrm{Ag}$ nanocages can be considered to be effective nanoabsorbers, whereas
$\mathrm{SiO}_{2} / \mathrm{Au}$ nanoshells and $\mathrm{Au}$ nanostars comprise both absorbing and strong scattering modalities. For applications in a broad spectral range, one should use composite Au-Ag nonspherical or/and inhomogeneous nanostructures, whose plasmon resonances can be tuned across the vis-NIR spectral band. Additional optical and other properties can be achieved through covering the plasmonic core with a mesoporous silica shell doped with various fluorescent, photodynamic, or/and other molecular cargos.

GNP conjugates with biospecific probes can 
serve as immunochemical markers for analytical purposes. For example, several colorimetric, static, and dynamic light scattering analytical techniques have been developed that employed aggregation phenomena induced by biospecific interactions between conjugates and targets. We have shown here how conjugates of different colors can be used in standard or multiplexed dot immunoassay techniques, which does not require any equipment to identify a positive reaction (section 3.3). In particular, we have demonstrated, for the first time, the use of antituberculin antibodies for GNP-based immunoassay of mycobacteria. Furthermore, conjugates of different shapes and structures can easily be identified by TEM analysis. This idea has been exemplified here by an unprecedented simultaneous TEM localization of antigens on the A. brasilense surface and polar flagella with two types of conjugates based on 15-nm GNPs and 40-nm nanocages.

In section 4, we have shown quite different images of living SPEV-2 cells incubated with two types of light-scattering GNPs (50-nm gold nanospheres and $80-\mathrm{nm}$ nanostars) and various dyes. It has been demonstrated how different microscopic techniques (TL, DF, and FL) and laser confocal microscopy can provide useful information about particle localization and penetration of dyes into cells. For example, we have observed atypical colocalization of chloroplasts and nanostars within the cells just near the leaf surface.

GNP-based nanocomposites seem to be a promising multifunctional platform, combining various diagnostic and therapeutic modalities. We have used such composites for combined photodynamic and photothermal treatment of pathogenic bacteria and xenografted tumors in rats. Finally, one important note is in order here. As demonstrated recently by Yang et al. [79] with a pregnant mice model, the materno-fetal transfer of GNPs is strongly age-dependent. It would be quite desirable to extend this conclusion to pregnant rats. In any case, we have shown [80] that both 5-nm and 30-nm particles can penetrate the placental barrier before the 11th gestational day. We also believe that the materno-fetal transfer of GNPs should depend on particle size and shape and on the surface moieties of functionalized GNPs (primarily, on the GNP charge and hydrophobic properties of GNPs).

After this manuscript had been accepted, we became aware of a pioneering study by Takahashi and Matsuoka [92] on cross placental transfer of 5- and $30-\mathrm{nm}{ }^{198} \mathrm{Au}$ colloids in near term rats.

\section{Acknowledgements}

This research was supported by grants from the Russian Foundation for Basic Research, the Programs of the Presidium of the Russian Academy of Sciences "Basic Sciences for Medicine" and "Basic Technologies for Nanostructures and Nanomaterials", and the Government of the Russian Federation (a grant to support scientific research projects implemented under the supervision of leading scientists at Russian institutions of higher education). VK was supported by a scholarship from the President of the Russian Federation. TP was supported by the Bortnik Foundation grant UMNIK. We thank G. Burygin, E. Panfilova, A. Burov, Ye. Lyubun (IBPPM RAS), O. Bibikova, A. Bashkatov, E. Genina, V. Tuchin, E. Tuchina (SSU), A. Bucharskaya (Saratov Medical University), and R. Khairullin (USU) for the collaborative work described in this review. We thank D.N. Tychinin (IBPPM RAS) for his help in preparation of the manuscript.

\section{Competing Interests}

The authors have declared that no competing interest exists.

\section{References}

1. Dykman LA, Khlebtsov NG. Gold nanoparticles in biomedical applications: recent advances and perspectives. Chem Soc Rev. 2012; 41: 2256-82.

2. Dreaden EC, Alkilany AM, Huang X, Murphy CJ, El-Sayed MA. The golden age: gold nanoparticles for biomedicine. Chem Soc Rev. 2012; 41: 2740-79.

3. Matteini P, Ratto F, Rossi F, Centi S, Dei L, Pini R. Chitosan films doped with gold nanorods as laser-activatable hybrid bioadhesives. Adv Mater. 2010; 22: 4213-16

4. Khlebtsov NG. Optics and biophotonics of nanoparticles with a plasmon resonance. Quantum Electron. 2008; 38: 504-29.

5. Quinten M. Optical properties of nanoparticle systems. Weinheim: Wliey-VCH Verlag; 2011.

6. Stockman MI. Nanoplasmonics: past, present, and glimpse into future. Opt Express. 2011; 19: 22029-106.

7. Picard FJ, Bergeron MG. Rapid molecular theranostics in infectious diseases. Drug Discov Today. 2002; 7: 1092-101.

8. Chen X. Introducing Theranostics journal - from the Editor-in-Chief. Theranostics 2011; 1: 1-2.

9. Hleb EY, Hu Y, Drezek RA, Hafner JH, Lapotko DO. Photothermal bubbles as optical scattering probes for imaging living cells. Nanomedicine. 2008; 3: 797-812.

10. Wagner DS, Delk NA, Lukianova-Hleb EY, Hafner JH, Farach-Carson MC, Lapotko DO. The in vivo performance of plasmonic nanobubbles as cell theranostic agents in zebrafish hosting prostate cancer xenografts. Biomaterials. 2010; 31: 7567-7574.

11. Lukianova-Hleb EY, Hanna EY, Hafner JH, Lapotko DO. Tunable plasmonic nanobubbles for cell theranostics. Nanotechnology. 2010; 21: 085102.

12. Lukianova-Hleb EY, Oginsky AO, Samaniego AP, Shenefelt DL, Wagner D.S, Hafner JH, et al. Tunable plasmonic nanoprobes for theranostics of prostate cancer. Theranostics. 2011; 1: 3-17.

13. Lammers T, Aime S, Hennink WE, Storm G, Kiessling F. Theranostic nanomedicine. Acc Chem Res. 2011; 44: 1029-38.

14. Funkhouser J. Reinventing pharma: the theranostic revolution. Curr Drug Discov. 2002; 2: 17-9.

15. Warner S. Diagnostics + therapy $=$ theranostics. Scientist. 2004; 18: 38-9. 
16. Kelkar SS, Reineke TM. Theranostics: combining imaging and therapy. Bioconjug Chem. 2011; 22: 1879-903.

17. Loo C, Lin A, Hirsch L, Lee M-H, Barton J, Halas N, West J, Drezek R. Nanoshell-enabled photonics-based imaging and therapy of cancer. Technol Cancer Res Treat. 2004; 3: 33-40.

18. Lapotko D, Lukianova E, Oraevsky A. Selective laser nano-thermolysis of human leukemia cells with microbubbles generated around clusters of gold Nanoparticles. Lasers Surg Med. 2006; 38: 631-42.

19. Hleb Y, Hafner JH, Myers JN, Hanna EY, Rostro BC, Zhdanok SA, Lapotko DO. LANTCET: elimination of solid tumor cells with photothermal bubbles generated around clusters of gold nanoparticles. Nanomedicine. 2008; 3: 647-67.

20. Khlebtsov B, Panfilova E, Khanadeev V, Bibikova O, Terentyuk G, Ivanov A, et al. Nanocomposites containing silica-coated gold-silver nanocages and $\mathrm{Yb}$-2,4-dimethoxyhematoporphyrin: Multifunctional capability of IR-luminescence detection, photosensitization, and photothermolysis. ACS Nano. 2011; 5: 7077-89.

21. Cheng S-H, Lee C-H, Chen M-C, Souris JS, Tseng F-G, Yang C-S, et al. Tri-functionalization of mesoporous silica nanoparticles for comprehensive cancer theranostics - the trio of imaging, targeting and therapy. J Mater Chem. 2010; 20: 6149-57.

22. Yu MK, Park J, Jon S. Targeting strategies for multifunctional nanoparticles in cancer imaging and therapy. Theranostics. 2012; 2: 3-34.

23. Alkilany A, Murphy CJ. Toxicity and cellular uptake of gold nanoparticles; what we have learned so far? J Nanopart Res. 2010; 12: 2313-33.

24. Khlebtsov NG, Dykman LA. Biodistribution and toxicity of engineered gold nanoparticles: a review of in vitro and in vivo studies. Chem Soc Rev. 2011; 40: 1647-71.

25. Faulk W, Taylor G. An immunocolloid method for the electron microscope. Immunochemistry. 1971; 8: 1081-83.

26. Weissleder R. A clearer vision for in vivo imaging. Nat Biotechnol. 2001; 19: 316-17.

27. Boisselier E., Astruc D. Gold nanoparticles in nanomedicine: preparations, imaging, diagnostics, therapies and toxicity. Chem Soc Rev. 2009; 38: $1759-82$.

28. Khlebtsov BN, Khlebtsov NG. On the measurement of gold nanoparticle sizes by the dynamic light scattering method. Colloid J. 2011; 73: 118-27.

29. Pylaev $\mathrm{T}$, Khanadeev $\mathrm{V}$, Khlebtsov B, Dykman L, Bogatyrev $\mathrm{V}$, Khlebtsov N. Colorimetric and dynamic light scattering detection of DNA sequences by using positively charged gold nanorods and nanospheres: A comparative study. Nanotechnology. 2011; 22: 285501.

30. Khlebtsov B, Khanadeev V, Khlebtsov N. Tunable depolarized light scattering from gold and gold/silver nanorods. Phys Chem Chem Phys. 2010; 12: 3210-18

31. Khlebtsov BN, Khanadeyev VA, Ye J, Mackowski DW, Borghs G, Khlebtsov NG. Coupled plasmon resonances in monolayers of metal nanoparticles and nanoshells. Phys Rev B. 2008; 77: 035440.

32. Khlebtsov BN, Khanadeev VA, Panfilova EV, Pylaev TE, Bibikova OA, Staroverov SA, et al. New types of nanomaterials: powders of gold nanospheres, nanorods, nanostars, and gold-silver nanocages. Nanotechnologies in Russia. 2012; in press.

33. Khlebtsov BN, Khanadeev VA, Maksimova IL, Terentyuk GS, Khlebtsov NG. Silver nanocubes and gold nanocages: fabrication and optical and photothermal properties. Nanotechnologies in Russia. 2010; 5: 454-68.

34. Khlebtsov BN, Tuchina ES, Khanadeev VA, Panfilova EV, Petrov PO, Tuchin VV, et al. Enhanced photoinactivation of Staphylococcus aureus with nanocomposites containing plasmonic particles and hematoporphyrin. J Biophotonics. 2012; doi 10.1002/jbio.201200079.

35. Khlebtsov BN, Panfilova EV, Terentyuk GS, Maksimova IL, Ivanov AV, Khlebtsov NG. Plasmonic nanopowders for photothermal therapy of tumors. Langmuir. 2012; 28: 8994-9002.

36. Liz-Marzán LM. Tailoring surface plasmons through the morphology and assembly of metal nanoparticles. Langmuir. 2006; 22: 32-41.

37. Yu Y-Y, Chang S-S, Lee C-L, Wang CRC. Gold nanorods: electrochemical synthesis and optical properties. J Phys Chem B. 1997; 101: 6661-64.

38. Oldenburg S, Averitt RD, Westcott S, Halas NJ. Nanoengineering of optical resonances. Chem Phys Lett. 1998; 288: 243-47.

39. Ni W, Kou X, Yang Z, Wang J. Tailoring longitudinal surface plasmon wavelengths, scattering and absorption cross sections of gold nanorods. ACS Nano. 2008; 2: 677-86.

40. Brinson BE, Lassiter JB, Levin CS, Bardhan R, Mirin N, Halas NJ. Nanoshells made easy: improving Au layer growth on nanoparticle surfaces. Langmuir. 2008; 24: 14166-171.

41. Liu M, Guyot-Sionnest P. Synthesis and optical characterization of $\mathrm{Au} / \mathrm{Ag}$ core/shell nanorods. J Phys Chem B. 2004; 108: 5882-88.
42. Sun $Y, X i a$ Y. Shape-controlled synthesis of gold and silver nanoparticles. Science. 2002; 298: 2176-79.

43. Khlebtsov NG, Dykman LA. Optical properties and biomedical applications of plasmonic nanoparticles. J Quant Spectrosc Radiat Transfer. 2010; 111: 1-35.

44. Leuvering JHW, Thal PJHM, van der Waart M, Schuurs AHWM. Sol particle immunoassay (SPIA). J Immunoassay. 1980; 1: 77-91.

45. Dykman LA, Krasnov YaM, Bogatyrev VA, Khlebtsov NG. Quantitative immunoassay method based on extinction spectra of colloidal gold bioconjugates. Proc SPIE. 2001; 4241: 37-41.

46. Leuvering JHW, Coverde BC, Thal PJHM., Schuurs AHWM. A homogeneous sol particle immunoassay for human chorionic gonadotrophin using monoclonal antibodies. J Immunol Meth. 1983; 60: 9-23.

47. Neely A, Perry C, Varisli B, Singh AK, Arbneshi T, Senapati D, et al. Ultrasensitive and highly selective detection of Alzheimer's disease biomarker using two-photon Rayleigh scattering properties of gold nanoparticle. ACS Nano. 2009; 3: 2834-40.

48. Wang X, Li Y, Wang H, Fu Q, Peng J, Wang Y, et al. Gold nanorod-based localized surface plasmon resonance biosensor for sensitive detection of hepatitis B virus in buffer, blood serum and plasma. Biosens Bioelectron. 2010; 26: 404-10.

49. Dykman LA, Bogatyrev VA, Khlebtsov BN, Khlebtsov NG. A protein assay based on colloidal gold conjugates with trypsin. Anal Biochem. 2005; 341: 16-21.

50. Mullis KB, Faloona FA. Specific synthesis of DNA in vitro via a polymerase-catalyzed chain reaction. Methods Enzymol. 1987; 155: 335-50.

51. Espy MJ, Uhl JR, Sloan LM, Buckwalter SP, Jones MF, Vetter EA, et al. Real-time PCR in clinical microbiology: Applications for routine laboratory testing. Clin Microbiol Rev. 2002; 19: 165-256.

52. Mirkin CA, Letsinger RL, Mucic RC, Storhoff JJ. A DNA-based method for rationally assembling nanoparticles into macroscopic materials. Nature. 1996; 382: 607-09.

53. Li H, Rothberg LJ. Label-free colorimetric detection of specific sequences in genomic DNA amplified by polymerase chain reaction. J Am Chem Soc. 2004; 126: 10958-61.

54. Dai Q, Liu X, Coutts J, Austin L, Huo Q. A one-step highly sensitive method for DNA detection using dynamic light scattering. J Am Chem Soc. 2008; 130: 8138-39.

55. He W, Huang CZ, Li YF, Xie JP, Yang RG, Zhou PF, et al. One-step label-free optical genosensing system for sequence-specific DNA related to the human immunodeficiency virus based on the measurements of light scattering signals of gold nanorods. Anal Chem. 2008; 80: 8424-30.

56. Khlebtsov BN, Dykman LA, Bogatyrev VA, Zharov V, Khlebtsov NG. A solid-phase dot assay using silica/gold nanoshells. Nanoscale Res Lett. 2007; 2: 6-11.

57. Khlebtsov BN, Khlebtsov NG. Enhanced solid-phase immunoassay using gold nanoshells: effect of nanoparticle optical properties. Nanotechnology. 2008; 19: 435703.

58. Panfilova E, Shirokov A, Khlebtsov B, Matora L, Khlebtsov N. Multiplexed dot immunoassay using $\mathrm{Ag}$ nanocubes, $\mathrm{Au} / \mathrm{Ag}$ alloy nanoparticles, and $\mathrm{Au} / \mathrm{Ag}$ nanoboxes. Nano Research. 2012; 5: 124-34.

59. Bashan $Y$, de-Bashan LE. How the plant growth-promoting bacterium Azospirillum promotes plant growth - a critical assessment. Adv Agron. 2010; 108: 77-136.

60. Ozekinci T, Ozbek E, Celik Y. Comparison of tuberculin skin test and a specific T-cell-based test, T-Spot.TB, for the diagnosis of latent tuberculosis infection. J Int Med Res. 2007; 35: 696-703.

61. Staroverov SA, Vidyasheva IV, Gabalov KP, Vasilenko OA, Laskavyi VN, Bogatyrev VA, et al. Use of gold nanoparticles to prepare polyclonal antibodies against tuberculin and to study the mechanisms of humoral response development. Laboratory diagnosis. Eastern Europe. 2012; 2: 43-9.

62. Fujimoto JG, Farkas DL (Eds.). Biomedical optical imaging. New York: Oxford University Press, 2009.

63. Wang G, Fang N. Detecting and tracking nonfluorescent nanoparticle probes in live cells. Methods Enzymol. 2012; 504: 83-108.

64. El-Sayed IH, Huang $\mathrm{XH}$, El-Sayed MA. Surface plasmon resonance scattering and absorption of anti-EGFR antibody conjugated gold nanoparticles in cancer diagnostics: applications in oral cancer. Nano Lett. 2005; 5: 829-34.

65. Wang S-H, Lee C-W, Chiou A, Wei P-K. Size-dependent endocytosis of gold nanoparticles studied by three-dimensional mapping of plasmonic scattering images. J Nanobiotechnology. 2010; DOI-10.1186/1477-3155-8-33.

66. Wang G, Stender AS, Sun W, Fang N. Optical imaging of non-fluorescent nanoparticle probes in live cells. Analyst. 2010; 135: 215-21. 
67. Sokolov K, Follen M, Aaron J, Pavlova I, Malpica A, Lotan R, Richards-Kortum R. Real-time vital optical imaging of precancer using anti-epidermal growth factor receptor antibodies conjugated to gold nanoparticles. Cancer Res. 2003; 63: 1999-2004.

68. Maiorano G, Sabella S, Sorce B, Brunetti V, Malvindi MA, Cingolani R, Pompa PP. Effects of cell culture media on the dynamic formation of protein-nanoparticle complexes and influence on the cellular response. ACS Nano. 2010; 4: 7481-91.

69. Blab GA, Cognet L, Berciaud S, Alexandre I, Husar D, Remacle J, and Lounis B. Optical readout of gold nanoparticle-based DNA microarrays without silver enhancement. Biophys J. 2006; 90: L13-L15.

70. Wang H, Huff TB, Zweifel DA, He W, Low PS, Wei A, et al. In vitro and in vivo two-photon luminescence imaging of single gold nanorods. Proc Natl Acad Sci USA. 2005; 102: 15752-56.

71. Durr NJ, Larson T, Smith DK, Korgel BA, Sokolov K, Ben-Yakar A. Two-photon luminescence imaging of cancer cells using molecularly targeted gold nanorods. Nano Lett. 2007; 7: 941-45.

72. Talbot CB, Patalay R, Munro I, Warren S, Ratto F, Matteini P, et al. Application of ultrafast gold luminescence to measuring the instrument response function for multispectral multiphoton fluorescence lifetime imaging. Opt Express. 2011; 19: 13848-61.

73. Yelin D, Oron D, Thiberge S, Moses E, Silberberg Y. Multiphoton plasmon-resonance microscopy. Opt Express. 2003; 11: 1385-91.

74. Oh E, Delehanty JB, Sapsford KE, Susumu K, Goswami R, Blanco-Canosa $\mathrm{JB}$, et al. Cellular uptake and fate of PEGylated gold nanoparticles is dependent on both cell-penetration peptides and particle size. ACS Nano. 2011; 5: 6434-48

75. Dam DHM, Lee J.H, Sisco PN, Co DT, Zhang M, Wasielewski MR, et al. Direct observation of nanoparticle- cancer cell nucleus interactions. ACS Nano. 2012; 6: 3318-26.

76. Kobori T, Watanabe J, Naka H. Gold nanoparticles as localization markers for direct and live imaging of particle absorption through a Caco-2 cell monolayer using dark-field microscopy. Anal Sci. 2012; 28: 61-64.

77. Hutter E, Boridy S, Labrecque S, Lalancette-Hebert M, Kriz J, Winnik FM, et al. Microglial response to gold nanoparticles. Acs Nano. 2010; 4: 2595-2606.

78. Kuo W-Sh, Chang Ch-N, Chang Yi-T, Yeh Ch.-Sh. Chem Commun. 2009;: 4853-55.

79. Yang H, Sun C, Fan Z, Tian X, Yan L, Du L, et al. Effects of gestational age and surface modification on materno-fetal transfer of nanoparticles in murine pregnancy. Sci Rep. 2012; 2: 847.

80. Tsyganova NA, Terentyuk GS, Khlebtsov BN, Bogatyrev VA, Dykman LA, Erykov SN, et al. Penetration of pegylated gold nanoparticles through rat placenta. B Exp Biol Med. 2012; accepted.

81. Huang X, Jain PK, El-Sayed IH, El-Sayed MA. Plasmonic photothermal therapy (PPTT) using gold nanoparticles. Lasers Med Sci. 2008; 23: 217-28.

82. Lapotko D. Therapy with gold nanoparticles and lasers: what really kills the cells? Nanomedicine. 2009; 4: 253-56.

83. Lapotko DO. Plasmonic nanoparticle-generated photothermal bubbles and their biomedical applications. Nanomedicine. 2009; 7: 813-845.

84. Khlebtsov BN, Zharov VP, Melnikov AG, Tuchin VV, Khlebtsov NG. Optical amplification of photothermal therapy with gold nanoparticles and nanoclusters. Nanotechnology. 2006; 7: 167-79.

85. Cole JR, Mirin NA, Knight MW, Goodrich GP, Halas NJ. Photothermal efficiencies of nanoshells and nanorods for clinical therapeutic applications. J Phys Chem C. 2009; 113: 12090-94.

86. Cheng FY, Chen CT, Yeh CS. Comparative efficiencies of photothermal destruction of malignant cells using antibodycoated silica@ Au nanoshells, hollow $\mathrm{Au} / \mathrm{Ag}$ nanospheres and $\mathrm{Au}$ nanorods. Nanotechnology. 2009; 20: 425104.

87. Richardson HH, Carlson MT, Tandler PJ, Hernandez P, Govorov AO. Experimental and theoretical studies of light-to-heat conversion and collective heating effects in metal nanoparticle solutions. Nano Lett. 2009; 9:1139-46

88. Chen H, Shao L, Ming T, Sun Z, Zhao C, Yang B, Wang J. Understanding the photothermal conversion efficiency of gold nanocrystals. Small. 2010; 6: 2272-80.

89. Pattan VP, Tunnell JW. Nanoparticle-mediated photothermal therapy: a comparative study of heating for different particle types. Lasers Surg Med. 2012; 44: 675-84.

90. Terentyuk GS, Maslyakova GN, Suleymanova LV, Khlebtsov BN, Kogan $\mathrm{BYa}$, Akchurin GG, et al. Circulation and distribution of gold nanoparticles and induced alterations of tissue morphology at intravenous particle delivery. J Biophoton. 2009; 2: 292-302.
91. Huang X, Peng X, Wang Y, Wang Y, Shin DM, El-Sayed MA, et al. A reexamination of active and passive tumor targeting by using rod-shaped gold nanocrystals and covalently conjugated peptide ligands. ACS Nano. 2010; 4: 5887-96.

92. Takanashi S, Matsuoka O. Cross placental transfer of ${ }^{198} \mathrm{Au}$ colloid in near term rats. J Radiat Res. 1981; 22: 242-249. 